\title{
Do latitudinal gradients exist in New Zealand stream invertebrate metacommunities?
}

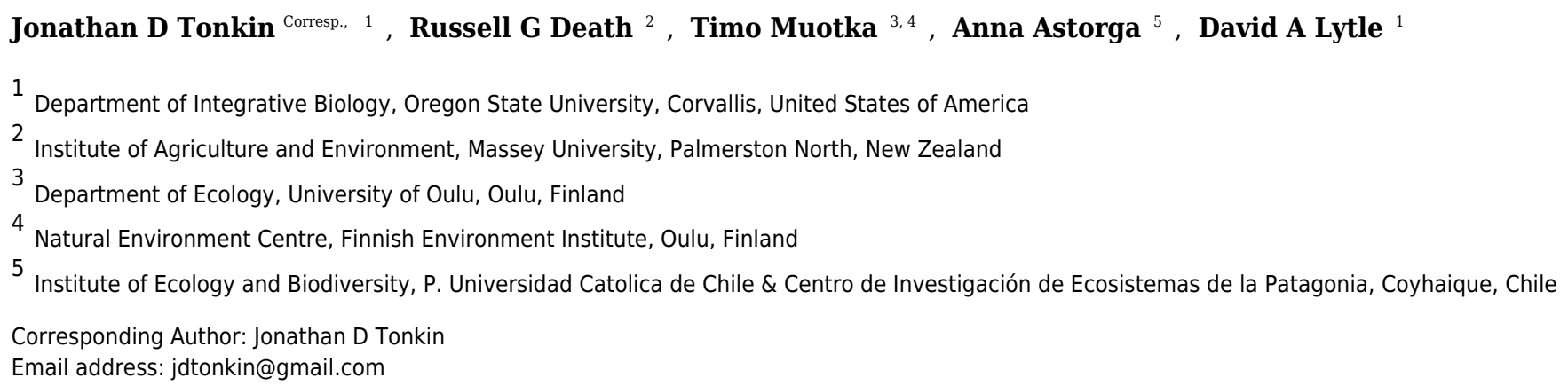

That biodiversity declines with latitude is well known, but whether a metacommunity process is behind this gradient has received limited attention. We tested the hypothesis that dispersal limitation is progressively replaced by mass effects with increasing latitude, along with a series of related hypotheses. We explored these hypotheses by examining metacommunity structure in stream invertebrate metacommunities spanning the length of New Zealand's two largest islands $(\sim 1300 \mathrm{~km})$, further disentangling the role of dispersal by deconstructing assemblages into strong and weak dispersers. Given the highly dynamic nature of New Zealand streams, our alternative hypothesis was that these systems are so unpredictable (at different stages of post-flood succession) that metacommunity structure is highly context dependent from region to region. We rejected our primary hypotheses, pinning this lack of fit on the strong unpredictability of New Zealand's dynamic stream ecosystems and fauna that has evolved to cope with these conditions. While local community structure turned over along this latitudinal gradient, metacommunity structure was highly context dependent and dispersal traits did not elucidate patterns. Moreover, the emergent metacommunity types exhibited no trends, nor did the important environmental variables. These results provide a cautionary tale for examining singular metacommunities. The considerable level of unexplained contingency suggests that any inferences drawn from one-off snapshot sampling may be misleading and further points to the need for more studies on temporal dynamics of metacommunity processes. 
1 Do latitudinal gradients exist in New Zealand stream

2 invertebrate metacommunities?

3

4 Jonathan D. Tonkin ${ }^{1 *}$, Russell G. Death², Timo Muotka ${ }^{3,4}$, Anna Astorga ${ }^{5}$, David A.

5 Lytle $^{1}$

6

7 'Department of Integrative Biology, Oregon State University, Corvallis, Oregon 97331,

8 USA

$9 \quad{ }^{2}$ Institute of Agriculture and Environment, Massey University, Palmerston North, New

10 Zealand

11 3Department of Ecology, University of Oulu, P.O. Box 3000, FI-90014, Finland

12 4Finnish Environment Institute, Natural Environment Centre, P.O. Box 140, FI-00251

13 Helsinki, Finland

$14{ }^{5}$ Institute of Ecology and Biodiversity, P. Universidad Catolica de Chile \& Centro de

15 Investigación de Ecosistemas de la Patagonia, Coyhaique, Chile

16

17 *Corresponding author: Jonathan D. Tonkin, jdtonkin@gmail.com. 


\section{Abstract}

19 That biodiversity declines with latitude is well known, but whether a metacommunity

20 process is behind this gradient has received limited attention. We tested the hypothesis

21 that dispersal limitation is progressively replaced by mass effects with increasing

22 latitude, along with a series of related hypotheses. We explored these hypotheses by

23 examining metacommunity structure in stream invertebrate metacommunities spanning

24 the length of New Zealand's two largest islands $(\sim 1300 \mathrm{~km})$, further disentangling the

25 role of dispersal by deconstructing assemblages into strong and weak dispersers. Given

26 the highly dynamic nature of New Zealand streams, our alternative hypothesis was that

27 these systems are so unpredictable (at different stages of post-flood succession) that

28 metacommunity structure is highly context dependent from region to region. We

29 rejected our primary hypotheses, pinning this lack of fit on the strong unpredictability of

30 New Zealand's dynamic stream ecosystems and fauna that has evolved to cope with

31 these conditions. While local community structure turned over along this latitudinal

32 gradient, metacommunity structure was highly context dependent and dispersal traits

33 did not elucidate patterns. Moreover, the emergent metacommunity types exhibited no

34 trends, nor did the important environmental variables. These results provide a

35 cautionary tale for examining singular metacommunities. The considerable level of unexplained contingency suggests that any inferences drawn from one-off snapshot sampling may be misleading and further points to the need for more studies on temporal dynamics of metacommunity processes.

\section{Introduction}

41 The latitudinal diversity gradient is among the most well-known patterns in ecology

42 (Hillebrand, 2004; Jocque et al., 2010). While general patterns of increasing richness

43 from the poles to the equator are common, there are many exceptions (Gaston \&

44 Blackburn, 2000; Hillebrand, 2004; Heino, 2011). The potential mechanisms behind this 45 gradient are broad, whether non-biological (e.g. mid-domain effect hypothesis; Colwell 46 \& Lees, 2000), ecological (e.g. species-energy hypothesis; Currie, 1991), or evolutionary/historical (e.g. evolutionary rate and effective evolutionary time 
48 hypotheses; Mittelbach et al., 2007), but incorporating variation among local 49 communities can provide additional insight (Qian \& Ricklefs, 2007; Qian et al., 2009; 50 Leprieur et al., 2011; Astorga et al., 2014). As a key mechanism behind the latitudinal 51 diversity gradient, climate increases in harshness with increasing latitude (Stevens, 52 1989). However, many other factors influence local climate including island size and the 53 level of isolation. Isolated oceanic islands, for instance, have lower seasonality and 54 predictability than continental locations at similar latitudes (Tonkin et al., 2017a, Fig. 1). 55 Jocque et al. (2010) argue that a shift in climatic stability with latitude drives a 56 dispersal-ecological specialisation trade-off at the metacommunity level, producing 57 gradients in dispersal ability, ecological specialisation, range size, speciation, and species richness. In particular, increased temporal variability in environmental conditions promotes increased dispersal ability of organisms (Dynesius \& Jansson, 2000; Jocque et al., 2010).

Community differences attributable to latitude are therefore likely to be driven by underlying metacommunity processes. Four metacommunity archetypes have been synthesised to summarise the relative roles of local (niche) and regional (dispersal) processes in community assembly (Leibold et al., 2004; Holyoak et al., 2005; Leibold \& Chase, 2018): neutral, patch dynamics, species sorting, and mass effects. What remains to be tested, however, is the influence that latitude has on the roles of different metacommunity processes (Jocque et al., 2010). In a testable hypothesis, Jocque et al. (2010) predicted a stronger role of dispersal limitation in the tropics accompanied by a shift to more species sorting and mass effects with increasing latitude.

Situated at mid-latitudes, New Zealand comprises a series of islands spanning a large latitudinal gradient. With a climate reflecting its oceanic position, rainfall (Fig. 1) and river flow regimes are typically unpredictable (Winterbourn et al., 1981; Winterbourn, 1995). Although most streams tend to be perennial, the high variability in 74 rainfall (Heine, 1985) produces considerable variation in flows, with frequent, but 75 typically short-duration, spates and floods (Duncan, 1987). Coupled with their flashy 76 flow regimes comes a lack of seasonality in some food resources because of a 77 predominantly evergreen flora (Winterbourn et al., 1981; Thompson \& Townsend, 78 2000). These factors, combined with its highly dynamic geological history, making the 
79 country particularly sensitive to sea-level fluctuations during the Quaternary, ultimately 80 lead to a largely generalist, opportunistic, and seasonally asynchronous stream fauna 81 adapted to coping with these harsh conditions and climatic unpredictability (Winterbourn 82 et al., 1981; Winterbourn, 1995; Thompson \& Townsend, 2000). Most notably, New 83 Zealand streams feature a predominance of endemic genera, invertebrates with poorly synchronised and flexible life histories, and a predominance of non-specialist "collectorbrowser" species (Winterbourn, 1995). Consequently, New Zealand stream communities provide an interesting test case for investigating latitudinal controls on community structure.

To test a series of hypotheses related to metacommunity structuring across a broad latitudinal gradient, we explored gradients of stream invertebrate metacommunity structure (spatial structuring and environmental filtering) spanning the length of New Zealand's two largest islands $(\sim 1300 \mathrm{~km})$. As a secondary exploration, we examined the best-fit idealised 'metacommunity types' assigned through the Elements of Metacommunity Structure framework (EMS; Leibold \& Mikkelson, 2002). To further disentangle the role of dispersal, we deconstructed assemblages into strong and weak dispersers. Doing so can be fruitful for exploring processes behind latitudinal diversity gradients (Kneitel, 2016). Taking a multi-faceted approach across latitudinal gradients allows for identifying complementary patterns in factors shaping metacommunities, compared to local community structure, advancing our understanding of how communities assemble in such dynamic landscapes.

We tested the following primary hypotheses based on the predictions of Jocque et al. (2010): Metacommunities are primarily structured by environmental variables (in line with the species sorting archetype; $\mathrm{H}_{1 \mathrm{a}}$ ) and spatial variables increase in importance from north to south (representing increasing dispersal and in line with the mass effects archetype; $\left.H_{1 b}\right)$. The alternative to this hypothesis $\left(H_{1} A\right)$ is that, given the highly dynamic nature of New Zealand streams (Winterbourn et al., 1981), they are so unpredictable (at different stages of post-flood succession) that metacommunity structuring is context dependent from region to region. Because environmental heterogeneity and the spatial extent of metacommunities are important regulators of the 
110 which should increase the spatial signature in the metacommunity) (Heino et al.,

111 2015b), we also explored the influence of these factors on observed patterns. Using the

112 deconstructed dispersal groups, we tested the secondary hypothesis, based on the

113 predictions of Jocque et al. $(2010)\left(\mathrm{H}_{2}\right)$, that strong dispersers increase from north to 114 south. The EMS analysis was used as an additional exploratory analysis, thus we did 115 not form any specific hypotheses.

116

\section{Methods}

\section{Study sites}

119 We used data previously collected (Astorga et al., 2014) from 120 streams in eight

120 regions (15 sites in each region), spanning a latitudinal gradient of 12 degrees (Fig. 2).

121 Values of regional $\gamma$ and $\beta$ diversity, and mean $\alpha$ diversity are reported in Astorga et al.

122 (2014). These eight datasets span across the five biogeographic regions of the New

123 Zealand mainland (Di Virgilio et al., 2014): two in northern North Island, two in southern

124 North Island, one in central New Zealand, two in mid-South Island, and one in southern

125 South Island. Site selection followed a series of criteria, outlined in the following

126 sentences, to minimise differences between regions. Streams were sampled primarily in

127 protected areas (National or State Forest Parks) and were restricted to those with

128 maximum of $14 \%$ exotic forestry and $30 \%$ pasture in the upstream catchment. All sites

129 had a minimum intact riparian buffer of 50 m (Freshwater Ecosystems of New Zealand;

130 FENZ) (Leathwick et al., 2010) and were selected in proportion to FENZ classes in

131 regions. Sites were restricted to $<7 \mathrm{~m}$ wide headwater streams (order 1-3), with similar

132 aspect and with a rocky substrate, and sampling was confined to the riffle zone. Almost

133 all of New Zealand's landmass belongs to the temperate oceanic (Cfb) climate zone

134 (Peel et al., 2007). Although the large majority of our sampling sites were geographically

135 situated in this zone, some of the South Island sites (e.g. in Fiordland and Arthur's

136 Pass) likely fell on the border of temperate oceanic, subpolar oceanic (Cfc) and tundra

137 (ET) zones. Nevertheless, all sites were situated in areas without shortage of rainfall,

138 which has been described as "plentiful" but temporally variable in New Zealand (Heine,

139 1985), although there are more arid regions in eastern zones such as Hawke's Bay and 
140 central Otago. Therefore, all sites had permanent flow and the large majority of streams 141 were runoff fed.

142

143 Benthic macroinvertebrate sampling

144 Benthic macroinvertebrate sampling was performed between February and April 2006

145 (Austral summer/autumn) using two-minute kick-net (0.3-mm mesh) samples. Kicks

146 were performed with the goal of covering most of the microhabitats present in a ca. 100

$147 \mathrm{~m}^{2}$ riffle section. This approach captures ca. $75 \%$ of the benthic invertebrate species at

148 a site, covering $1.3 \mathrm{~m}^{2}$ of the benthos (Mykra et al., 2006). Samples were stored in $70 \%$

149 ethanol and later sorted and identified to the lowest possible taxonomic level (usually

150 genus or species, but certain difficult-to-identify species, such as chironomid midges

151 were left at higher taxonomic levels), following Winterbourn et al. (2000).

152 To help understand the role of dispersal (inherent in all of our hypotheses), we

153 focused our analysis on three data matrices: all species combined, species with high

154 dispersal ability, and species with low dispersal ability. These dispersal ability groups

155 were assigned based on pre-defined trait categories established for New Zealand

156 aquatic invertebrates (Doledec et al., 2006, 2011). Such a deconstruction approach is

157 commonly applied in riverine metacommunity studies, and can help to disentangle the

158 effects of dispersal (Tonkin et al., 2018a). However, these dispersal traits do not

159 necessarily reflect actual dispersal rates (Lowe \& McPeek, 2014; Lancaster \& Downes,

160 2017). The analyses that follow used a combination of log- or Hellinger-transformed

161 abundance data or presence-absence data on a case-by-case basis, which we specify

162 below.

163

164 Environmental variables

165 We included several previously-identified important local habitat variables for stream

166 invertebrate communities (e.g. Tonkin, 2014; Astorga et al., 2014; Tolonen et al., 2017),

167 as well as stream order and elevation in our analyses (Table 1). Local habitat variables

168 were as follows: water temperature, electrical conductivity, $\mathrm{pH}$, wetted width, reach

169 slope, water depth, overhead canopy cover, periphyton biomass (chlorophyll a), 
170 bryophyte percent cover, Pfankuch index (bottom component), and substrate size index $171(\mathrm{SI})$.

172 Depth was measured at 40 random locations in transects across the channel.

173 Canopy cover was measured at 20 evenly-spaced cross-channel transects with a 174 densiometer. Channel slope was measured with an Abney level over 10-20 m.

175 Percentage of bryophytes was visually estimated for each reach. Substrate composition 176 was measured by taking 100 randomly-selected particles at $1-\mathrm{m}$ intervals along a path $17745^{\circ}$ to the stream bank in a zig-zag manner. Particles were assigned to each of 13 size 178 classes: bedrock, >300, 300-128, 128-90.5, 90.5-64, 64-45.3, 45.3-32, 32-22.6, $17922.6-16,16-11.3,11.3-88-5$, and $<5 \mathrm{~mm}$. These were then converted to a single 180 substrate size index $(\mathrm{SI})$ by summing the mid-point values of each size class weighted 181 by the number of stones in each class (bedrock was assigned a nominal size of 400 $182 \mathrm{~mm})$.

Stream bed stability was assessed with the bottom component of the Pfankuch 184 Stability Index (Pfankuch, 1975). The Pfankuch Index is a visual assessment method designed to give an index of channel stability. The index can be broken down into three individual components: upper banks, lower banks and stream bed (bottom). We used the bottom component as it is the most relevant to stream invertebrates (Schwendel et al., 2012). The bottom component consists of six wetted channel attributes (substrate brightness, angularity, consolidation, percentage of stable materials, scouring, and amount of clinging aquatic vegetation), which can be assigned to predetermined categories with weighted scores. The sum of these scores represents the stability of the substrate, where high values represent low stability.

As an assessment of periphyton biomass (measured as chlorophyll a: $\mu \mathrm{g} \mathrm{cm}^{2}$ ) at each site, five stones were randomly selected from the sample riffle and frozen for later analysis. Pigments were extracted in the laboratory by soaking the stones in $90 \%$ acetone for $24 \mathrm{~h}$ at $5^{\circ} \mathrm{C}$ in the dark. Absorbances were read using a Cary 50TM Conc UV-Visible spectrophotometer, and chlorophyll a was calculated using the method of Steinman \& Lamberti (1996). Stone surface area was corrected using the method of Graham et al. (1988), assuming only the top half of the stone was available for periphyton growth. 
202 Statistical analyses

203 Summarising patterns across regions

204 To visualise patterns in the environmental conditions of sites, we used Principal 205 Components Analysis (PCA), performed with the princomp function, on the full suite of 206 normalised environmental variables. Similarly, to examine patterns in macroinvertebrate communities across all 120 sites, we performed ordination with non-metric multidimensional scaling (nMDS), on $\log (x)+1$ abundance data. We ran this using the metaMDS function, based on Bray-Curtis distances, in the vegan package (Oksanen et al., 2013). To test whether communities differed across the eight regions, we used PERMANOVA, based on the adonis function and 999 permutations in vegan. To compare the properties of diversity in each of our eight regions, and gain insight into

213 how well sampled each region was, we calculated species accumulation curves (SAC)

214 using the specaccum function in vegan (exact method; Ugland et al., 2003). To accompany these curves, we estimated total regional species richness using Chao's estimate (Chao, 1987), but it is important to note that this estimate is biased for open regions like those examined here.

Given the importance of spatial extent and environmental heterogeneity on metacommunity structuring, we calculated these for each metacommunity. For spatial extent, we calculated the convex hull of points making up each metacommunity using the chull function, followed by calculating the area of the polygon using the Polygon function. Therefore, spatial extent represents the total area that each metacommunity occupies on the landscape. For environmental heterogeneity, we calculated the homogeneity of group dispersions using the betadisper function in vegan, following the methods of Anderson (2006).

Metacommunity structuring and role of dispersal $\mathrm{H}_{1}$ was tested using a variance partitioning approach (Borcard et al., 1992; Peres-Neto et al., 2006), where we disentangled the relative influence of spatial and environmental variables on metacommunity structure of the eight metacommunities $(n=15)$ using

231 Hellinger-transformed macroinvertebrate community data. A stronger role of 
232 environmental variables in structuring metacommunities reflects a situation where 233 species sorting is strong, whereas stronger spatial structuring (i.e. spatial variables 234 explain community structure) could reflect either end of the dispersal spectrum from 235 limitation to surplus. To partition variation, we used partial redundancy analysis (pRDA), 236 a constrained ordination technique, to partition the variation into the pure components of 237 space, environment and their shared contribution to the explanation of community 238 structure. Variance partitioning attempts to isolate the pure effects of environmental 239 gradients from spatial structure (i.e. environmental filtering) and the pure effects of 240 spatial structure from environmental gradients (i.e. dispersal effects). Note, however, 241 that if environmental and spatial variation overlap considerably, the spatial component

242 from variance partitioning analyses should be interpreted with caution (Gilbert \& 243 Bennett, 2010; Tuomisto et al., 2012). Shared remaining variation may result from 244 interactive effects such as spatially structured environmental gradients or dispersal that 245 is dependent on topography, for instance, but unmeasured environmental variables may 246 also be interpreted as pure spatial effects. The environmental component in our 247 analysis represents the set of pre-selected local habitat variables, and we represented 248 the spatial structuring through Principal Coordinates of Neighbour Matrices (PCNM). We created a set of spatial eigenvectors to represent the distribution of sites in 250 space using PCNM (Borcard \& Legendre, 2002; Dray et al., 2006) with the pcnm

251 function in the vegan package. PCNM transforms spatial distances between all sites in

252 a metacommunity based on a distance matrix into rectangular data for use in 253 constrained ordination methods. Despite the importance of the river network in 254 structuring riverine metacommunities (Tonkin et al., 2018b, 2018a), we focused on 255 overland distance to represent spatial structuring. This is because the large majority of 256 taxa in our dataset have an adult flight stage and can thus disperse overland, rather 257 than being restricted to within-network dispersal. Moreover, while there can be 258 differences in the influence of overland and watercourse distances (Schmera et al., 259 2018), such differences are often weak when considering invertebrates (Tonkin et al., 260 2018a). To create the PCNM vectors, we used geographic coordinates to create a 261 distance matrix using Euclidean distances. PCNM vectors represent a gradient of 262 organisation of sites at different spatial scales, ranging from large-scale to small. That 
263 is, PCNM1 represents the broadest-scale arrangement of sites, through to the last 264 vector representing much finer arrangement. Only eigenvectors with positive 265 eigenvalues were used in the analysis.

266 Prior to variance partitioning, we first ran global RDA models individually for 267 environment (normalised local habitat, stream order and elevation) and space (PCNM 268 vectors), and tested for significance. We checked for collinearity in the models and excluded variables with a variance inflation factor (VIF) of greater than 10. We removed the variable with the highest VIF first and followed each model sequentially until no variables had a VIF > 10. After this, if the global model was significant, we then performed forward selection to select the most important variables. We used the ordiR2step function in the vegan package (Oksanen et al., 2013) to forward-select variables, which employs the approach outlined by Blanchet et al. (2008). The ordiR2step function selects variables that maximise the adjusted $R^{2}\left(\operatorname{adj} . R^{2}\right)$ at each step. The stepwise procedure stops when the adj. $R^{2}$ begins to decline, exceeds the scope of the full model (i.e. full model adj. $R^{2}$ ), or the $P$ value, which we set to be 0.05 , is exceeded. If the global model was non-significant, we regarded that dataset to have an $R^{2}$ of 0 . Only if both spatial and environmental models were significant, was variance partitioning performed between the two groups. We partitioned the variation between forward-selected environmental variables and forward-selected spatial vectors using pRDA with the varpart function in vegan, and tested significance of the pure effects of environment and space using the RDA function.

To test $\mathrm{H}_{2}$, whether strong dispersers increase from north to south, we calculated the ratio of strong to weak dispersers in each metacommunity in full. All analyses, including the following, were performed in $R$ version 3.1.1 (R Core Team, 2014).

Elements of Metacommunity Structure (EMS) In addition to our core hypothesis testing, we employed the EMS framework (Leibold \& Mikkelson, 2002) as an exploratory examination of metacommunity types along the latitudinal gradient. EMS is an approach used to explore and characterise emergent properties in a site-by-species matrix, using three metrics: (1) coherence, or the degree to which different species respond to the same environmental gradient; (2) turnover 
294 (range turnover), or the degree to which species replace each other along the 295 environmental gradient; and (3) boundary clumping, or the amount of (dis)similarity 296 (i.e. clumping) in species range boundaries. EMS differs from the variance partitioning 297 approach in that it concurrently examines multiple idealised types of metacommunities, 298 by comparing observed patterns against null expectation.

299 Prior to extracting these elements, the site-by-species matrix is organised in the 300 most coherent manner using reciprocal averaging (Gauch et al., 1977). Reciprocal 301 averaging arranges sites so that the species with the most similar distributions and sites 302 with similar composition are closest in the matrix (Gauch et al., 1977); essentially 303 arranging sites along a latent environmental gradient which is likely important in 304 structuring species distributions. The ordered site-by-species matrix is then compared 305 with random distributions through permutation of a null matrix.

EMS takes a three-step approach to measuring coherence, turnover, and 307 boundary clumping. Only when a matrix has significantly positive coherence, can the 308 following steps be performed. Coherence, the first step, can be differentiated into non309 significant (i.e. random: species assemble independent of each other), significantly negative (i.e. checkerboard), or significantly positive (i.e. coherent). Checkerboard patterns represent distributions where species are found in avoidance of each other more often than chance. Checkerboards were originally thought to reflect competitive exclusion (Diamond, 1975), but can also represent a host of other causes such as environmental heterogeneity (Gotelli \& McCabe, 2002; Boschilia et al., 2008). At each of the steps, the observed ordinated site-by-species matrix is compared with a null distribution. The matrix is reshuffled based on a predefined algorithm and constraints and permuted a set number of times. The observed value is then compared with the 318 null.

Coherence is calculated through the number of embedded absences in the ordinated matrix. Embedded absences are gaps in the species range (Leibold \& Mikkelson, 2002). If there are more embedded absences than expected by chance

322 (i.e. through the null matrix), a metacommunity is considered checkerboarded, and vice versa (i.e. fewer embedded absences than chance). If there is no difference in the observed matrix from chance (null), random assembly is expected. For comparability, 
325 both coherence and turnover are tested using the standardised z-test. Coherent 326 distributions suggest communities are structured along an environmental gradient, 327 either individualistically or in groups. Turnover and boundary clumping are then 328 examined on the positively coherent distributions.

329 The turnover step enables differentiation into the set of gradient models that best 330 fit the data structure. Turnover is measured as the number of times a species replaces 331 another between two sites in the ordinated matrix. Significantly negative turnover points 332 to nestedness in distributions (further described below), whereas significantly positive 333 can be differentiated into Clementsian, Gleasonian or evenly-spaced gradients. These 334 latter three can be distinguished based on the level of boundary clumping in species 335 distributions, using Morista's Index (Morista, 1971) and an associated Chi test comparing observed and null distributions. Values significantly greater than 1 point to clumped range boundaries (i.e. Clementsian gradients), less than one point to hyperdispersed range boundaries (i.e. evenly-spaced gradients), and no difference from one points to random range boundaries (i.e. Gleasonian gradients). Nested subsets are also broken down based on their boundary clumping into clumped, hyperdispersed and 341 random range boundaries.

342 Rather than adopt the approach of Presley et al. (2010), where non-significant 343 turnover is further examined into quasi-turnover and quasi-nestedness, we treated non344 significant turnover as a non-structure given that it indicates no difference from the null 345 expectation. Eight possible metacommunity types result: random, checkerboard, 346 Gleasonian, Clementsian, evenly-spaced, nested clumped, nested random, and nested 347 evenly-spaced. Detailed explanation and diagrammatic representations of these 348 structures are available in several sources (e.g. Leibold \& Mikkelson, 2002; Presley et al., 2010; Tonkin et al., 2017b).

We constrained our null models using the fixed-proportional "R1" method (Gotelli, 2000), which maintains site richness, but fills species ranges based on their marginal probabilities. The R1 null model is realistic from an ecological perspective, given that richness of a site varies along ecological gradients (Presley et al., 2009). Consequently, the R1 null model is recommended in the EMS analysis as it is relatively insensitive to type I and II errors (Presley et al., 2009). Other methods can incorporate too much or 
356 too little biology into the null model and can be thus prone to type I and II errors (Gotelli, 357 2000; Presley et al., 2009). Using the R1 null model, generated in the vegan package 358 (Oksanen et al., 2013), we produced 1000 simulated null matrices for each test. We 359 evaluated EMS on presence-absence data, using the $R$ package Metacom (Dallas, 360 2014), across the eight metacommunities individually and restricted our examination to 361 the primary axis of the RA ordination as this represents the best arrangement of 362 matrices. Prior to running the EMS analysis, we removed all species that were present 363 in less than two sites, as rare species can bias the EMS results, particularly coherence 364 and boundary clumping (Presley et al., 2009).

365

366

367 The Fiordland and Northland metacommunities had the greatest spatial extents (Fig. $3682 \mathrm{E}$ ), but there was little difference in environmental heterogeneity between the regions 369 (Fig. 2F). The gradient in environmental conditions was weak across the eight regions, 370 with a low percentage of variance explained (37\%) by the first two principal components 371 (Fig. 2B), and no variables contributing more than 15\% to either of the first two 372 components. Invertebrate communities differed significantly between the eight regions, 373 with a clear latitudinal trend in assemblage structure (PERMANOVA: $F_{7,112}=7.30, R^{2}=$ $3740.313, P=0.001$; Fig. 2 C). Regional richness tended to be highest at the north of each 375 island and decline towards the southern zones (Fig. 2D), as demonstrated in Astorga et 376 al. (2014). The regional pool of most regions were well sampled. However, Kahurangi

377 did not reach a clear asymptote and had the steepest species accumulation curve.

378 Moreover, the North Island regions' curves tended to be less steep compared to those 379 in the South Island. However, Chao's estimated values did not differ in a systematic 380 manner, with differences between sampled and projected richness not being 381 consistently higher in the South Island.

382

383 Metacommunity structuring and the role of dispersal

384 There was no gradient with latitude in the relative importance of environmental or spatial 385 control for all species combined and for individual dispersal groups (Fig. 3) suggesting 
$386 \mathrm{H}_{1}$ can be rejected. The influence of spatial extent and its interaction with dispersal 387 ability did not resolve this lack of pattern in the relative role of spatial or environmental 388 components in the variance partitioning models (Fig. 2-4). Finally, contrary to $\mathrm{H}_{2}$, the 389 ratio of strong to weak dispersers decreased from north to south (Fig. 4).

When considering all species together, only three of the eight regions were 391 significantly structured by both environmental and spatial components together, and 392 thus could be considered for variance partitioning (Fig. 3). In the deconstructed 393 dispersal group datasets, only one of the eight regions had combined significant 394 environmental and spatial components. Environmental control was more commonly 395 important than spatial in structuring both strong and weak disperser metacommunities. Northland exhibited no spatial or environmental structure for any of the datasets.

Considering all models (including those assigned $0 \%$ explained), environmental 398 variables explained more of the variation when the whole community was considered 399 (mean Adj. $R^{2}=0.134 ; 13.4 \%$ variance explained) compared to breaking into high 400 $(7.1 \%)$ and low $(4.8 \%)$ dispersal ability groups. This result was particularly evident for certain regions, such as Westland, which could be explained well when considering the 402 full community (strongest model), but not for the dispersal groups. However, strong 403 dispersers had on average higher adjusted $R^{2}$ values (Adj. $R^{2}=0.191 ; 19.1 \%$ explained) when only considering the significant models, than all combined $(18.0 \%)$ or 405 weak dispersers (9.6\%). Spatial variables explained less of the variation in community 406 structure than environmental, when non-significant models were included (Adj. $R^{2}$ - All: 0.047; High: 0.049; Low: 0.054) but not when only considering significant models (Adj. $R^{2}$ - All: 0.126; High: 0.200; Low: 0.143).

Forward-selected environmental variables were highly variable in the RDA models, 410 with no particular variable consistently important across the eight metacommunities

411 (Table 2; Table S1 in Appendix S1).

412

\section{Metacommunity types (EMS)}

414 There was no latitudinal trend in metacommunity type for all organisms combined and 415 for each of the dispersal ability groups (Table 3). For the full community dataset, 416 Gleasonian gradients were the most common pattern (five regions), indicating positive 
417 coherence and turnover, but no boundary clumping. The remaining regions'

418 metacommunity types consisted of two regions with random structures and one with no 419 structure (non-signficant turnover). Clementsian gradients were more common for 420 strong dispersers, with the remaining regions having either random (two regions), 421 Gleasonian or no structure (non-signficant turnover; Table 3). Weak dispersers were 422 much more variable between the regions, often with weaker coherence. In fact, four 423 regions exhibited random distributions represented by non-signficant coherence. The 424 remaining regions had either Gleasonian (two regions), Clementsian and no structure.

425 Egmont (Clementsian) and Westland (random) had the same pattern between high and 426 low dispersal ability groups. Tararua consistently exhibited weak patterns with either 427 random or no structure, and Westland metacommunities were always randomly 428 distributed.

429

\section{Discussion}

431 As a result of the relatively high latitude of New Zealand and based on the hypotheses 432 of Jocque et al. (2010), we hypothesised $\left(\mathrm{H}_{1}\right)$ a dominant role of species sorting and 433 dispersal surplus (reflecting the mass effects archetype) in structuring these 434 assemblages $\left(\mathrm{H}_{1 \mathrm{a}}\right)$ and an increasing dispersal surplus from north to south $\left(\mathrm{H}_{1 \mathrm{~b}}\right)$.

435 However, despite a latitudinal gradient present in assemblages at the community level 436 overall and within each island for regional $\gamma$ diversity (as well as $\alpha$ and $\beta$ diversity, 437 Astorga et al., 2014), what emerged at the metacommunity level was more 438 idiosyncratic. In particular, there was no latitudinal trend in either environmental 439 vs. spatial control (rejecting $\mathrm{H}_{1 \mathrm{~b}}$ ) or the idealised metacommunity types tested through 440 the EMS analysis at both the full community level and for dispersal groups. Lack of fit to 441 the hypothesis of Jocque et al. (2010) likely reflects the dynamic, unpredictable nature 442 of New Zealand streams (partially supporting $\mathrm{H}_{1} \mathrm{~A}$ ).

$443 \quad$ New Zealand comprises a series of mid-latitude islands, with a typically 444 unpredictable climate (Fig. 1) and flashy river flow regimes (Winterbourn et al., 1981) 445 reflecting its oceanic position. At a single time-point, communities are therefore most 446 likely at different stages of post-flood recolonisation $\left(H_{1} A\right)$. Antecedent conditions are 447 not only important for dynamic systems like these, but also for more continental 
448 climates. For instance, preceding-year climatic conditions have been demonstrated to 449 be more important in shaping European stream invertebrate communities than long450 term climatic trends (Jourdan et al., 2018). The dynamism of streams, particularly in 451 oceanic climates, represents a fundamentally important factor controlling 452 metacommunity dynamics, with assembly mechanisms varying temporally in dynamic 453 streams (Datry et al., 2016; Sarremejane et al., 2017). The relative roles of local and 454 regional processes will depend on the amount of time that has passed for dispersal and 455 colonisation to play out (Brendonck et al., 2014). With the central importance of natural 456 cycles of flooding and drought in streams (Poff et al., 1997; McMullen et al., 2017;

457 Tonkin et al., 2018c), it stands to reason that antecedent flow conditions play a key role 458 in structuring metacommunities in streams (Campbell et al., 2015).

459 The lack of seasonality and predictability in New Zealand's climate likely plays a 460 strong role in the low predictability in metacommunity structuring. The hypothesis of 461 Jocque et al. (2010) does not take into account differences in island size and isolation, 462 fundamental aspects controlling biodiversity (MacArthur \& Wilson, 1967). Island and 463 mainland locations at similar latitudes do not comprise the same climatic patterns 464 (Tonkin et al., 2017a), with continental locations having much greater predictability in 465 their seasonality compared to islands. To demonstrate this point, we compared a 30-y 466 sequence of monthly rainfall totals from the central North Island of New Zealand with 467 Western Australia, a Mediterranean climate, using wavelet analysis (Fig. 1) (Torrence \& 468 Compo, 1998). Although this is just one of the locations examined in our study, which 469 vary in their rainfall regimes, we use this simple comparison to demonstrate the extent 470 of climatic unpredictability present in this region compared to a predictable climatic 471 zone. Figure 1 demonstrates clearly the strongly seasonal and predictable pattern 472 apparent in Western Australia, with a significant and repeatable cycle at the 1-y time 473 period over the full sequence. By contrast, central New Zealand's climate exhibits no 474 repeatability in the rainfall, with very few time points in the sequence indicating any 475 power at the 1-y period.

$476 \quad$ New Zealand streams have other features that may limit their fit to our primary 477 hypotheses, some of which are shared by other island localities, including: rivers tend to 478 be short, swift and steep due to the narrow landmass and tectonically active nature; 
479 evergreen vegetation dominates the flora; and riparian vegetation is scarce for much of 480 their length leading to a predominance of autochthonous rather than allochthonous 481 control of river food webs (Winterbourn et al., 1981; Thompson \& Townsend, 2000). As 482 such, New Zealand streams are considered as being physically, rather than biologically, 483 dominated systems (Winterbourn et al., 1981). These factors, in conjunction with its 484 highly dynamic geological history, have led to the evolution of a stream invertebrate 485 fauna with flexible and poorly synchronised life histories, and generalist feeding 486 behaviour (Winterbourn et al., 1981; Thompson \& Townsend, 2000; Scarsbrook, 2000). 487 Although New Zealand stream invertebrate communities are not necessarily less 488 species rich or different in terms of food web structure to overseas locations, there is a 489 clear paucity of shredder species in particular, with generalist browsers predominating 490 communities (Thompson \& Townsend, 2000). Under these circumstances, it is not 491 surprising that metacommunity dynamics can be difficult to predict, as we clearly 492 demonstrate, without a strong temporal resolution in the data. Thus, in support of our 493 alternative first hypothesis, despite the large latitudinal gradient examined, predictable 494 metacommunity dynamics appear to be masked by short-term unpredictability in 495 environmental conditions.

496 Results were highly idiosyncratic between different regions, with considerable 497 variability in the relative roles of environmental and spatial structuring, important 498 environmental variables, and the idealised metacommunity types, with no real match 499 between the two approaches. This context dependence did not reflect an interaction 500 between spatial extent and dispersal ability. Although much of this unpredictability may 501 be related to the unpredictable characteristics of New Zealand streams, it is pertinent to 502 recognise that this is a challenge facing many stream metacommunity studies globally, 503 where patterns differ considerably between different catchments (Heino et al., 2012, 504 2015a; Tonkin et al., 2016a). Lawton (1999) pinpointed this problem in ecology over a 505 decade ago suggesting that community ecology is rife with contingency, so much so 506 that generality is unlikely. Lawton goes on to highlight that the problem is indeed most 507 severe at the intermediate organisational level of communities, compared to more 508 predictable lower (e.g. populations) or higher levels (e.g. macroecology).

509 Metacommunities are indeed difficult systems to predict, with processes affecting 
510 different subsets of organisms and operating at specific times (Driscoll \& Lindenmayer, 511 2009). One source of context dependence in metacommunity structuring is differences 512 between different trait modalities, such as dispersal modes (Thompson \& Townsend, 513 2006; Canedo-Arguelles et al., 2015; Tonkin et al., 2016b). Thus, if spatial extent and 514 dispersal limitation were interacting to structure the metacommunity, deconstructing the 515 full assemblage into dispersal groups (e.g. strong vs. weak dispersers) should have 516 helped to explain discrepancies in our predictions, but this was not the case.

517 Nevertheless, we must also entertain the possibility that greater spatial replication would 518 have strengthened the observed patterns.

519 Finally, contrary to the expectation of Jocque et al. (2010) that dispersal ability 520 increases moving away from the equator $\left(\mathrm{H}_{2}\right)$, we found a decrease in the ratio of 521 strong to weak dispersers moving from north to south. Theoretically, temporal variability 522 in environmental conditions promotes increased dispersal ability of organisms

523 (Dynesius \& Jansson, 2000; Jocque et al., 2010); an hypothesis strongly tied with 524 Rapoport's rule of increasing range size with increasing latitude (Stevens, 1989) and 525 one that receives support from the population genetics literature via increased genetic 526 divergence among populations nearer the equator (e.g. Eo et al., 2008). However, it is 527 important to note that while dispersal ability can play a strong role in determining 528 species range sizes, its influence may be less common than previously thought (Lester 529 et al., 2007). Although there is evidence that weak dispersers have stronger latitudinal 530 diversity gradients than strong dispersers in Europe, the mechanisms behind this are 531 related to the ability of organisms to recolonise northern sites following glaciation (e.g.

532 Baselga et al., 2012); a different issue to that experienced in New Zealand. The 533 conflicting result we observed may reflect several factors. 1. Lack of time for dispersal 534 and colonisation to play out post-disturbance (Brendonck et al., 2014; Campbell et al., 535 2015). 2. The requirement of a longer latitudinal gradient for these mechanisms to play 536 out. Over the length of New Zealand, the continuity of habitat availability in space and 537 time, a key mechanism behind Jocque et al. (2010), likely differs very little. 3. Climatic 538 idiosyncrasies not reflecting a north-south gradient and thus not selecting for a gradually 539 increased dispersal ability at higher latitudes. 


\section{Conclusions}

542 Jocque et al. (2010) highlighted the fundamental role of dispersal in driving the

543 latitudinal diversity gradient, suggesting a climate-mediated dispersal-ecological

544 specialisation trade-off as a key factor regulating this pattern. We tested several

545 hypotheses based on those of Jocque et al. (2010) relating to how New Zealand stream

546 invertebrate metacommunity structure changed along a broad latitudinal gradient, and

547 examining the mediating role of dispersal. We rejected our primary hypotheses, finding

548 that: 1 . species sorting appears to be weak or inconsistent, and its influence did not

549 change predictably with latitude; and 2 . weaker dispersers increased with latitude. We

550 associate this lack of fit to these hypotheses on the strong unpredictability of New

551 Zealand's dynamic stream ecosystems (supporting $\mathrm{H}_{1} \mathrm{~A}$ ) and a fauna that has evolved

552 to cope with these conditions. While local community structure turned over along this

553 latitudinal gradient, metacommunity structure was highly context dependent and

554 dispersal traits did not elucidate patterns.

555 These results, along with other recent findings (Heino et al., 2012, 2015a; Tonkin 556 et al., 2016a), provide a cautionary tale for examining singular metacommunities. The

557 considerable level of unexplained context dependency suggests that any inferences 558 drawn from one-off snapshot sampling may be misleading. Given the importance of 559 understanding metacommunity processes for the successful management of river 560 ecosystems (Siqueira et al., 2012; Heino, 2013; Tonkin et al., 2014; Stoll et al., 2016;

561 Swan \& Brown, 2017), this level of unpredictability is a major cause for concern. While 562 spatial replication of multiple metacommunities may elucidate some of this uncertainty, 563 studies on temporal dynamics of metacommunity processes are clearly needed. We 564 therefore urge researchers to consider the temporal dynamic, particularly in relation to 565 seasonal cycles and their predictability.

566

\section{Acknowledgements}

568 We thank Fiona Death, Manas Chakraborty and Riku Paavola for field and laboratory 569 assistance. Jenny Jyrkänkallio-Mikkola, Felix Picazo Mota, and two anonymous 570 reviewers improved earlier versions of the manuscript. 


\section{References}

573 Anderson M.J. (2006) Distance-based tests for homogeneity of multivariate dispersions. $574 \quad$ Biometrics, 62, 245-253.

575 Astorga A., Death R., Death F., Paavola R., Chakraborty M., \& Muotka T. (2014) Habitat 576 heterogeneity drives the geographical distribution of beta diversity: the case of $577 \quad$ New Zealand stream invertebrates. Ecology and Evolution, 4, 2693-702.

578 Baselga A., Lobo J.M., Svenning J.-C., Aragón P., \& Araújo M.B. (2012) Dispersal 579 580 ability modulates the strength of the latitudinal richness gradient in european beetles. Global Ecology and Biogeography, 21, 1106-1113.

581

582

583

584

585

586

587

588

589

590

591

592

593

594

595

596

597

598

599

600

601

602

Blanchet F., Legendre P., \& Borcard D. (2008) Forward selection of explanatory variables. Ecology, 89, 2623-2632.

Borcard D. \& Legendre P. (2002) All-scale spatial analysis of ecological data by means of principal coordinates of neighbour matrices. Ecological Modelling, 153, 51-68.

Borcard D., Legendre P., \& Drapeau P. (1992) Partialling out the spatial component of ecological variation. Ecology, 73, 1045-1055.

Boschilia S.M., Oliveira E.F., \& Thomaz S.M. (2008) Do aquatic macrophytes co-occur randomly? An analysis of null models in a tropical floodplain. Oecologia, 156, 203-214.

Brendonck L., Jocqué M., Tuytens K., Timms B.V., \& Vanschoenwinkel B. (2014) Hydrological stability drives both local and regional diversity patterns in rock pool metacommunities. Oikos, 124, 741-749.

Campbell R.E., Winterbourn M.J., Cochrane T.A., \& McIntosh A.R. (2015) Flow-related disturbance creates a gradient of metacommunity types within stream networks. Landscape Ecology, 30, 667-680.

Canedo-Arguelles M., Boersma K.S., Bogan M.T., Olden J.D., Phillipsen I., Schriever T.A., \& Lytle D.A. (2015) Dispersal strength determines meta-community structure in a dendritic riverine network. Journal of Biogeography, 42, 778-790.

Chao A. (1987) Estimating the population size for capture-recapture data with unequal catchability. Biometrics, 43, 783.

Colwell R. \& Lees D.C. (2000) The mid-domain effect: Geometric constraints on the geography of species richness. Trends in Ecology \& Evolution, 15, 70-76. 
603 Currie D.J. (1991) Energy and large-scale patterns of animal- and plant-species 604 richness. The American Naturalist, 137, 27-49.

605 Dallas T. (2014) metacom: an R package for the analysis of metacommunity structure. 606 Ecography, 37, 402-405.

607 Datry T., Bonada N., \& Heino J. (2016) Towards understanding the organisation of 608 metacommunities in highly dynamic ecological systems. Oikos, 125, 149-159.

609 Di Virgilio G., Laffan S.W., Ebach M.C., \& Chapple D.G. (2014) Spatial variation in the 610 climatic predictors of species compositional turnover and endemism. Ecology and $611 \quad$ Evolution, 4, 3264-3278.

612 Diamond J. (1975) Assembly of species communities. Ecology and evolution of 613

614 communities (ed. by M. Cody and J. Diamond), pp. 342-444. Harvard University

615 Doledec S., Phillips N., \& Townsend C. (2011) Invertebrate community responses to
$616 \quad$ land use at a broad spatial scale: Trait and taxonomic measures compared in
$617 \quad$ New Zealand rivers. Freshwater Biology, 56, 1670-1688. 616

Doledec S., Phillips N., \& Townsend C. (2011) Invertebrate community responses to
land use at a broad spatial scale: Trait and taxonomic measures compared in
New Zealand rivers. Freshwater Biology, 56, 1670-1688.

Doledec S., Phillips N., \& Townsend C. (2011) Invertebrate com
land use at a broad spatial scale: Trait and taxonomic meas
New Zealand rivers. Freshwater Biology, 56, 1670-1688.

619

620

621

622

623

624 Press,

Doledec S., Phillips N., Scarsbrook M., Riley R.H., \& Townsend C.R. (2006)

Comparison of structural and functional approaches to determining landuse effects on grassland stream invertebrate communities. Journal of the North American Benthological Society, 25, 44-60.

625 Driscoll D. \& Lindenmayer D.B. (2009) Empirical tests of metacommunity theory using 626 an isolation gradient. Ecological Monographs, 79, 485-501.

627 Duncan M.J. (1987) River hydrology and sediment transport. Inland waters of new 628 zealand (ed. by A.B. Viner), pp. 113-137. Department of Scientific; Industrial 629 Research Bulletin 241, Wellington, NZ.

630 Dynesius M. \& Jansson R. (2000) Evolutionary consequences of changes in species' 631 geographical distributions driven by milankovitch climate oscillations.

632 Proceedings of the National Academy of Sciences, 97, 9115-9120. 
633 Eo S.H., Wares J.P., \& Carroll J.P. (2008) Population divergence in plant species reflects latitudinal biodiversity gradients. Biology Letters, 4, 382-384.

635

Gaston K. \& Blackburn T. (2000) Pattern and process in macroecology. Blackwell

636 Science Ltd., Oxford, UK,

Gauch H.G., Whittaker R.H., \& Wentworth T.R. (1977) A comparative study of reciprocal 638 averaging and other ordination techniques. Journal of Ecology, 65, 157-174.

639 Gilbert B. \& Bennett J.R. (2010) Partitioning variation in ecological communities: do the 640 numbers add up? Journal of Applied Ecology, 47, 1071-1082.

641 Gotelli N.J. (2000) Null model analysis of species co-occurrence patterns. Ecology, 81, 642 2606-2621.

643 Gotelli N.J. \& McCabe D.J. (2002) Species co-occurrence: a meta-analysis of J. M.

644 Diamond's assembly rules model. Ecology, 83, 2091-2096.

645 Graham A.A., McCaughan D.J., \& McKee F.S. (1988) Measurement of surface area of $646 \quad$ stones. Hydrobiologia, 157, 85-87.

647 Heine R. (1985) Climate and meteorological aspects of new zealand's water resources.

648 New Zealand agricultural science, 19, 152-156.

649 Heino J. (2011) A macroecological perspective of diversity patterns in the freshwater 650 realm. Freshwater Biology, 56, 1703-1722.

651 Heino J. (2013) The importance of metacommunity ecology for environmental 652 assessment research in the freshwater realm. Biological reviews of the Cambridge Philosophical Society, 88, 166-78.

654 Heino J., Grönroos M., Soininen J., Virtanen R., \& Muotka T. (2012) Context 655 656 dependency and metacommunity structuring in boreal headwater streams. Oikos,

657 Heino J., Melo A.S., Bini L.M., Altermatt F., Al-Shami S.A., Angeler D.G., Bonada N., 658 Brand C., Callisto M., Cottenie K., Dangles O., Dudgeon D., Encalada A., Göthe 659 E., Grönroos M., Hamada N., Jacobsen D., Landeiro V.L., Ligeiro R., Martins 660 661 662 R.T., Miserendino M.L., Md Rawi C.S., Rodrigues M.E., Roque F.D.O., Sandin L., Schmera D., Sgarbi L.F., Simaika J.P., Siqueira T., Thompson R.M., \& Townsend C.R. (2015a) A comparative analysis reveals weak relationships between 
663

664

665

666

667

668

669

670

671

672

673

674

675

676

677

678

679

680

681

682

683

684

685

686

687

688

689

690

691

692

693

ecological factors and beta diversity of stream insect metacommunities at two spatial levels. Ecology and Evolution, 5, 1235-1248.

Heino J., Melo A.S., Siqueira T., Soininen J., Valanko S., \& Bini L.M. (2015b) Metacommunity organisation, spatial extent and dispersal in aquatic systems: patterns, processes and prospects. Freshwater Biology, 60, 845-869.

Hillebrand H. (2004) On the generality of the latitudinal diversity gradient. American Naturalist, 163, 192-211.

Holyoak M., Leibold M.A., Mouquet N., Holt R.D., \& Hoopes M.F. (2005) Metacommunities - A framework for large-scale community ecology. Metacommunities: Spatial Dynamics and Ecological Communities, 1-31.

Jocque M., Field R., Brendonck L., \& De Meester L. (2010) Climatic control of dispersalecological specialization trade-offs: a metacommunity process at the heart of the latitudinal diversity gradient? Global Ecology and Biogeography, 19, 244-252.

Jourdan J., O'Hara R.B., Bottarin R., Huttunen K.-L., Kuemmerlen M., Monteith D., Muotka T., Ozolinš D., Paavola R., Pilotto F., Springe G., Skuja A., Sundermann A., Tonkin J.D., \& Haase P. (2018) Effects of changing climate on european stream invertebrate communities: A long-term data analysis. Science of The Total Environment, 621, 588-599.

Kneitel J.M. (2016) Climate-driven habitat size determines the latitudinal diversity gradient in temporary ponds. Ecology, 97, 961-968.

Lancaster J. \& Downes B.J. (2017) Dispersal traits may reflect dispersal distances, but dispersers may not connect populations demographically. Oecologia, 184, 171182.

Lawton J.H. (1999) Are there general laws in ecology? Oikos, 84, 177-192.

Leathwick J.R., West D., Gerbeaux P., Kelly D., Robertson H., Brown D., Chadderton W., \& Ausseil A.-G. (2010) Freshwater ecosystems of New Zealand (fenz) geodatabase. Users guide. 57 .

Leibold M.A. \& Chase J.M. (2018) Metacommunity ecology. Volume 59, Princeton University Press, Princeton, USA.

Leibold M.A. \& Mikkelson G.M. (2002) Coherence, species turnover, and boundary clumping: elements of meta-community structure. Oikos, 97, 237-250. 
694 Leibold M.A., Holyoak M., Mouquet N., Amarasekare P., Chase J.M., Hoopes M.F., Holt 695 R.D., Shurin J.B., Law R., Tilman D., Loreau M., \& Gonzalez A. (2004) The 696 metacommunity concept: a framework for multi-scale community ecology. Ecology Letters, 7, 601-613.

698 Leprieur F., Tedesco P.A., Hugueny B., Beauchard O., Dürr H.H., Brosse S., \& 699 Oberdorff T. (2011) Partitioning global patterns of freshwater fish beta diversity

700 701 reveals contrasting signatures of past climate changes. Ecology Letters, 14, 325-

702 334.

703

704

705

706

707

708

709

710

711

712

Mittelbach G.G., Schemske D.W., Cornell H.V., Allen A.P., Brown J.M., Bush M.B.,

713

714

715

716

717

718

719

720

721

722

723

Lester S.E., Ruttenberg B.I., Gaines S.D., \& Kinlan B.P. (2007) The relationship between dispersal ability and geographic range size. Ecology Letters, 10, 745758.

Lowe W.H. \& McPeek M.A. (2014) Is dispersal neutral? Trends in Ecology \& Evolution, 29, 444-450.

MacArthur R.H. \& Wilson E.O. (1967) The Theory of Island Biogeography. Princeton University Press, Princeton, New Jersey.

McMullen L.E., Leenheer P.D., Tonkin J.D., \& Lytle D.A. (2017) High mortality and enhanced recovery: Modelling the countervailing effects of disturbance on population dynamics. Ecology Letters, 20, 1566-1575. Harrison S.P., Hurlbert A.H., Knowlton N., Lessios H.A., McCain C.M., McCune A.R., McDade L.A., McPeek M.A., Near T.J., Price T.D., Ricklefs R.E., Roy K., Sax D.F., Schluter D., Sobel J.M., \& Turelli M. (2007) Evolution and the latitudinal diversity gradient: Speciation, extinction and biogeography. Ecology Letters, 10, 315-331.

Morista M. (1971) Composition of the I-index. Researches on Population Ecology, 13, $1-27$.

Mykra H., Ruokonen T., \& Muotka T. (2006) The effect of sample duration on the efficiency of kick-sampling in two streams with contrasting substratum heterogeneity. Internationale Vereinigung fur Theoretische und Angewandte Limnologie Verhandlungen, 29, 1351-1355. 
724 Oksanen J., Blanchet F.G., Kindt R., Legendre P., Minchin P.R., O’Hara R.B., Simpson

725

726

727

728

729

730

731

732

733

734

735

736

737

738

739

740

741

742

743

744

745

746

747

748

749

750

751

752

G.L., Solymos P., Henry M., Stevens H., \& Wagner H. (2013) Vegan: Community Ecology Package. R package version 2.0-10. http://CRAN.Rproject.org/package=vegan .

Peel M.C., Finlayson B.L., \& McMahon T.A. (2007) Updated world map of the köppengeiger climate classification. Hydrology and Earth System Sciences Discussions, 4, 439-473.

Peres-Neto P., Legendre P., Dray S., \& Borcard D. (2006) Variation partitioning of species data matrices: estimation and comparison of fractions. Ecology, 87, 2614-2625.

Pfankuch D. (1975) Stream Reach Inventory and Channel Stability Evaluation.

Poff N.L., Allan J.D., Bain M.B., Karr J.R., Prestegaard K.L., Richter B.D., Sparks R.E., \& Stromberg J.C. (1997) The natural flow regime. BioScience, 47, 769-784.

Presley S.J., Higgins C.L., \& Willig M.R. (2010) A comprehensive framework for the evaluation of metacommunity structure. Oikos, 119, 908-917.

Presley S.J., Higgins C.L., López-González C., \& Stevens R.D. (2009) Elements of metacommunity structure of Paraguayan bats: multiple gradients require analysis of multiple ordination axes. Oecologia, 160, 781-93.

Qian H. \& Ricklefs R.E. (2007) A latitudinal gradient in large-scale beta diversity for vascular plants in north america. Ecology Letters, 10, 737-744.

Qian H., Badgley C., \& Fox D.L. (2009) The latitudinal gradient of beta diversity in relation to climate and topography for mammals in north america. Global Ecology and Biogeography, 18, 111-122.

R Core Team (2014) R: A language and environment for statistical computing.

Roesch A. \& Schmidbauer H. (2014) WaveletComp: Computational Wavelet Analysis. R package version 1.0 .

Sarremejane R., Cañedo-Argüelles M., Prat N., Mykrä H., Muotka T., \& Bonada N. (2017) Do metacommunities vary through time? Intermittent rivers as model systems. Journal of Biogeography, 44, 2752-2763. 
753 Scarsbrook M.R. (2000) Life-histories. New zealand stream invertebrates: Ecology and

754

755

756

757

758

759

760

761

762

763

764

765

766

767

768

769

770

771

772

773

774

775

776

777

778

779

780

781

782 implications for management (ed. by K.J. Collier and M.J. Winterbourn), pp. 7699. New Zealand Limnological Society, Hamilton,

Schmera D., Árva D., Boda P., Bódis E., Bolgovics, Borics G., Csercsa A., Deák C., Krasznai E. Á., Lukács B.A., Mauchart P., Móra A., Sály P., Specziár A., Süveges K., Szivák I., Takács P., Tóth M., Várbíró G., Vojtkó A.E., \& Erős T. (2018) Does isolation influence the relative role of environmental and dispersalrelated processes in stream networks? An empirical test of the network position hypothesis using multiple taxa. Freshwater Biology, 63, 74-85.

Schwendel A.C., Death R.G., Fuller I.C., \& Tonkin J.D. (2012) A new approach to assess bed stability relevant for invertebrate communities in upland streams. River Research and Applications, 28, 1726-1739.

Siqueira T., Bini L.M., Roque F.O., \& Cottenie K. (2012) A metacommunity framework for enhancing the effectiveness of biological monitoring strategies. PLOS ONE, 7 , e43626.

Steinman A.D. \& Lamberti G.A. (1996) Biomass and pigments of benthic algae. Methods in stream ecology (ed. by F.R. Hauer and G.A. Lamberti), pp. 295-314. Academic Press, San Diego, CA.

Stevens G.C. (1989) The latitudinal gradient in geographical range: How so many species coexist in the tropics. The American Naturalist, 133, 240-256.

Stoll S., Breyer P., Tonkin J.D., Früh D., \& Haase P. (2016) Scale-dependent effects of river habitat quality on benthic invertebrate communities - Implications for stream restoration practice. Science of The Total Environment, 553, 495-503.

Swan C.M. \& Brown B.L. (2017) Metacommunity theory meets restoration: Isolation may mediate how ecological communities respond to stream restoration. Ecological Applications, 27, 2209-2219.

Thompson R.M. \& Townsend C.R. (2000) New Zealand's stream invertebrate communities: an international perspective. New zealand stream invertebrates: Ecology and implications for management (ed. by K.J. Collier and M.J. Winterbourn), pp. 53-74. New Zealand Limnological Society, Hamilton, 
783 Thompson R.M. \& Townsend C.R. (2006) A truce with neutral theory: local deterministic

784

785

786

787

788

789

790

791

792

793

794

795

796

797

798

799

800

801

802

803

804

805

806

807

808

809

810

811

factors, species traits and dispersal limitation together determine patterns of diversity in stream invertebrates. Journal of Animal Ecology, 75, 476-484.

Tolonen K.E., Leinonen K., Erkinaro J., \& Heino J. (2017) Ecological uniqueness of macroinvertebrate communities in high-latitude streams is a consequence of deterministic environmental filtering processes. Aquatic Ecology, 52, 17-33.

Tonkin J.D. (2014) Drivers of macroinvertebrate community structure in unmodified streams. PeerJ, 2, e465.

Tonkin J.D., Altermatt F., Finn D.S., Heino J., Olden J.D., Pauls S.U., \& Lytle D.A. (2018a) The role of dispersal in river network metacommunities: Patterns, processes, and pathways. Freshwater Biology, 63, 141-163.

Tonkin J.D., Bogan M.T., Bonada N., Rios-Touma B., \& Lytle D.A. (2017a) Seasonality and predictability shape temporal species diversity. Ecology, 98, 1201-1216.

Tonkin J.D., Heino J., \& Altermatt F. (2018b) Metacommunities in river networks: The importance of network structure and connectivity on patterns and processes. Freshwater Biology, 63, 1-5.

Tonkin J.D., Heino J., Sundermann A., Haase P., \& Jähnig, Sonja C. (2016a) Context dependency in biodiversity patterns of central German stream metacommunities. Freshwater Biology, 61, 607-620.

Tonkin J.D., Merritt D.M., Olden J.D., Reynolds L.V., \& Lytle D.A. (2018c) Flow regime alteration degrades ecological networks in riparian ecosystems. Nature Ecology \& Evolution, 2, 86-93.

Tonkin J.D., Shah R.D.T., Shah D.N., Hoppeler F., Jähnig S.C., \& Pauls S.U. (2017b) Metacommunity structuring in Himalayan streams over large elevational gradients: the role of dispersal routes and niche characteristics. Journal of Biogeography, 44, 62-74.

Tonkin J.D., Stoll S., Jähnig S.C., \& Haase P. (2016b) Contrasting metacommunity structure and beta diversity in an aquatic-floodplain system. Oikos, 125, 686697. 
812 Tonkin J.D., Stoll S., Sundermann A., \& Haase P. (2014) Dispersal distance and the 813 pool of taxa, but not barriers, determine the colonisation of restored river reaches

814 by benthic invertebrates. Freshwater Biology, 59, 1843-1855.

815 Torrence C. \& Compo G.P. (1998) A practical guide to wavelet analysis. Bulletin of the $816 \quad$ American Meteorological Society, 79, 61-78.

817 Tuomisto H., Ruokolainen L., \& Ruokolainen K. (2012) Modelling niche and neutral 818 dynamics: On the ecological interpretation of variation partitioning results. $819 \quad$ Ecography, 35, 961-971.

820 Ugland K.I., Gray J.S., \& Ellingsen K.E. (2003) The species-accumulation curve and 821 estimation of species richness. Journal of Animal Ecology, 72, 888-897.

822 Winterbourn M.J. (1995) Rivers and streams of new zealand. River and stream 823 ecosystems of the world (ed. by C. Cushing C. E.), pp. 695-716. Elsevier Press, 824 New York,

825 Winterbourn M.J., Gregson K.L.D., \& Dolphin C.H. (2000) Guide to the aquatic insects 826 of New Zealand. Entomological Society of New Zealand, Auckland.

827 Winterbourn M.J., Rounick J.S., \& Cowie B. (1981) Are New Zealand stream 828 ecosystems really different? New Zealand Journal of Marine and Freshwater $829 \quad$ Research, 15, 321-328.

830 


\section{Figure 1 (on next page)}

Wavelet diagram comparing 30-year monthly rainfall values between central North Island New Zealand (A) and Mediterranean-climate Western Australia (B).

The $x$ axis represent the full time series of 30 years. The $y$ axis represents the range of frequencies (period) examined within the time series. Thus the plot shows power as a function of frequency over time. Wavelet power increases from blue (low power) to red (high power). Higher power represents greater strength of the periodicity. The figure illustrates a clear, repeatable annual rainfall cycle in Western Australia (i.e. strong and consistent power at the 12-month period over the full 30-year cycle) representative of its Mediterranean climate. This contrasts to the highly unpredictable rainfall cycles in New Zealand. Wavelet analysis was performed using the R package 'WaveletComp' (Roesch and Schmidbauer 2014). 
PeerJ

\section{A. New Zealand}

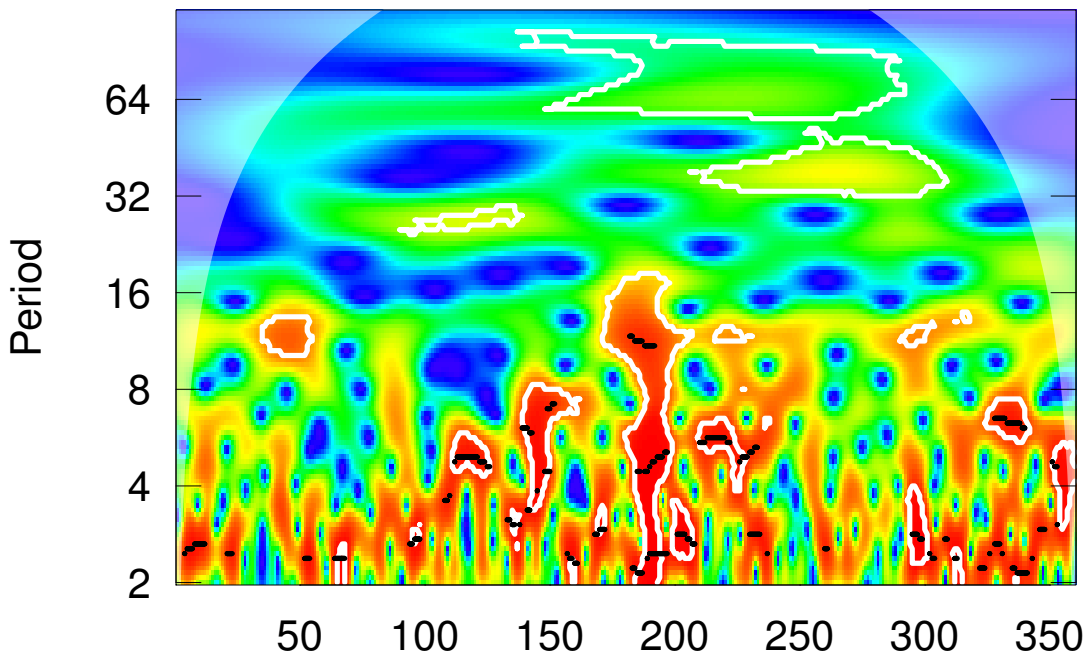

\section{B. Western Australia}

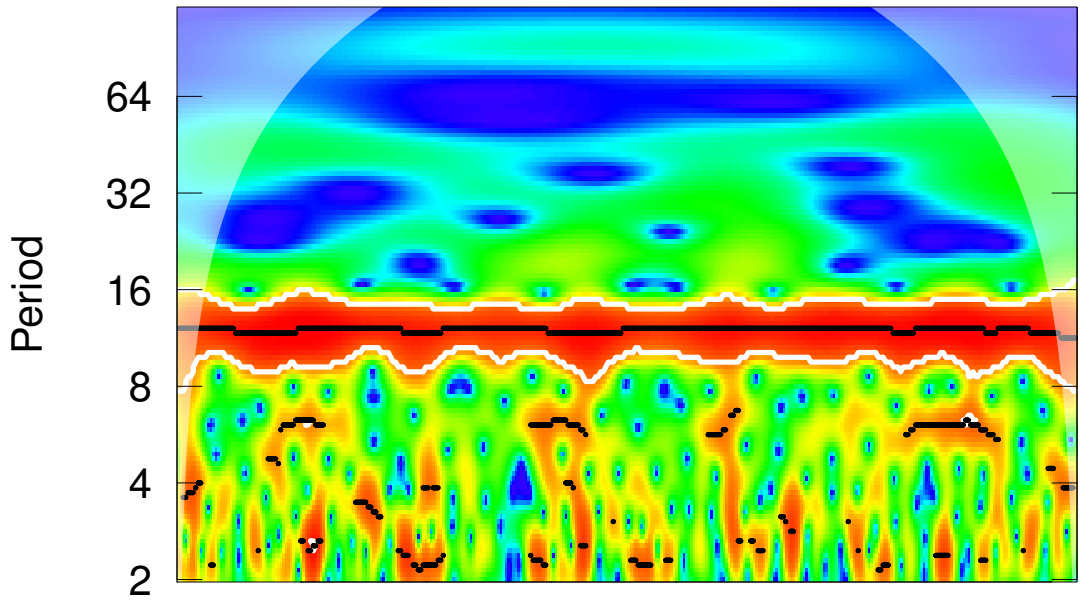

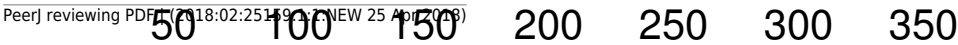




\section{Figure 2 (on next page)}

Overview of sites and regional invertebrate assemblages across New Zealand.

All plots are colour-coded and shaped in the same manner, from north to south. A.

Distribution of 120 sites across eight regions of New Zealand. The five biogeographic regions are displayed as letters alongside the plot (N: Northern North Island; SN: Southern North Island; C: Central New Zealand; MS: mid-South Island; S: Southern South Island). B. First two components of principal component analysis on environmental variables used in the study. Proportion of variation explained: $\mathrm{PCA} 1=0.21 ; \mathrm{PCA} 2=0.17$. C. Non-metric multidimensional scaling ordination of invertebrate communities from all 120 sites. $2 \mathrm{D}$ stress $=0.21$. D. Species accumulation curves for all species for the eight regions. Regions are ordered from north (left) to south (right). Displayed text shows sampled regional richness (N) and Chao's estimate of total regional richness with standard error. E. Spatial extent of each metacommunity (normalised area). F. Environmental heterogeneity of each metacommunity, measured through homogeneity of dispersions. 


\section{Figure 3 (on next page)}

Results of variance partitioning of spatial and environmental variables on macroinvertebrate communities in eight regions spanning the length of New Zealand's two largest islands.

Regions are ordered from north (left) to south (right). Variance partitioning was performed only where global RDA models were significant. Certain regions had non-significant global models for either spatial, environmental or both. Where either spatial or environmental was significant, we plot the results of the global model (and its significance). Significance of the pure effects of space or environment are shown with asterisks. All $=$ all species, Strong $=$ strong dispersers, Weak $=$ weak dispersers. 
Figure 4 (on next page)

Ratio of strong to weak dispersers in each metacommunity.

$0=1: 1$ ratio of strong to weak dispersers. Above the line represents a higher strong to weak disperser ratio. 


\section{Table $\mathbf{1}$ (on next page)}

Environmental variables used in the analysis. 


\begin{tabular}{lll}
\hline Variable & Units & Explanation \\
\hline Temp & ${ }^{\circ} \mathrm{C}$ & Water temperature \\
Cond & $\mu \mathrm{S} \mathrm{cm}{ }^{-1}$ & Conductivity \\
pH & - & pH \\
Width & $\mathrm{cm}$ & Wetted width \\
Elev & $\mathrm{m} \mathrm{a.s.l.}$ & Elevation \\
Slope & $\mathrm{cm} \mathrm{m}{ }^{-1}$ & Slope of the stream reach \\
Depth & $\mathrm{cm}$ & Depth \\
OHCov & $\%$ & Percent overhead canopy cover \\
Chla & $\mu \mathrm{g} \mathrm{cm}^{-2}$ & Chlorophyll $a$ (periphyton biomass) \\
Bryophytes & $\%$ & Percent moss cover \\
Pfankuch_bottom & - & Stream bed stability \\
SI & - & Substrate size index \\
Order & - & Stream order \\
\hline
\end{tabular}




\section{Table 2 (on next page)}

Forward-selected environmental variables used in the variance partitioning analysis when a global RDA model was significant.

Only if a global model was significant, was forward selection performed. Forward-selected variables are given in the "Variables" column. Subset = subset of species (All species, and strong and weak dispersers). Full results of both global and forward-selected models, including spatial variables can be found in Table S1. 


\begin{tabular}{lllrl}
\hline Subset & Region & $\boldsymbol{F}$ & $\boldsymbol{P}$ & Variables \\
\hline All & U & 2.57 & 0.001 & Temp, pH \\
All & $\mathrm{E}$ & 2.96 & 0.001 & OHCov, Elev, SI, Depth \\
All & $\mathrm{K}$ & 2.25 & 0.001 & Cond, OHCov \\
All & A & 2.64 & 0.026 & Temp \\
All & W & 4.55 & 0.001 & Cond, pH, Slope \\
All & F & 2.13 & 0.01 & Order \\
Strong & E & 3.83 & 0.001 & OHCov, Elev, SI \\
Strong & K & 2.64 & 0.005 & Cond, Chla \\
Strong & A & 3.20 & 0.037 & Temp \\
Weak & U & 3.32 & 0.001 & Temp, pH \\
Weak & T & 2.57 & 0.001 & OHCov, Pfankuch_bottom, Chla, Depth \\
Weak & K & 2.20 & 0.024 & Cond \\
Weak & F & 2.13 & 0.018 & Order \\
\hline
\end{tabular}

1 


\section{Table 3 (on next page)}

Results of Elements of Metacommunity Structure analysis examining the best-fit idealised metacommunity structure for each metacommunity, including the strong and weak disperser groups.

Results are given for the first axis of reciprocal averaging ordination on the species by site matrices testing for coherence, species range turnover and boundary clumping in each metacommunity of 15 sites across eight regions of New Zealand. Subset = subset of species (all, and strong and weak dispersers), $\mathrm{df}=$ degrees of freedom, Abs = number of embedded absences, $\mathrm{Re}=$ number of replacements, $\mathrm{MI}=$ Morista's Index, $\mathrm{SD}=$ standard deviation. Mean and SD values are those calculated from the 1000 generated null matrices, based on the "R1" null model. Refer to Figure 1 for region names. '-' represents structures with nonsignificant turnover. 


\begin{tabular}{|c|c|c|c|c|c|c|c|c|c|c|c|c|c|c|c|}
\hline \multirow[b]{2}{*}{ Subset } & \multirow[b]{2}{*}{ Region } & \multirow[b]{2}{*}{ df } & \multicolumn{5}{|c|}{ Coherence } & \multicolumn{5}{|c|}{ Turnover } & \multicolumn{2}{|c|}{ Boundary clumping } & \multirow[b]{2}{*}{ Structure } \\
\hline & & & Abs & Mean & SD & $z$ & $P$ & Re & Mean & SD & $z$ & $P$ & MI & $P$ & \\
\hline All & $\mathrm{N}$ & 58 & 305 & 321.1 & 15 & 1.07 & 0.2835 & 2148 & 1649.8 & 580.7 & -0.86 & 0.3909 & 1.17 & 0.3468 & Random \\
\hline All & $\mathrm{U}$ & 68 & 277 & 386.6 & 17.7 & 6.18 & $<0.0001$ & 9768 & 2659.4 & 823.4 & -8.63 & $<0.0001$ & 0.85 & 0.3928 & Gleasonian \\
\hline All & $\mathrm{E}$ & 62 & 248 & 367.8 & 19.1 & 6.26 & $<0.0001$ & 10931 & 2978.5 & 980.3 & -8.11 & $<0.0001$ & 0.68 & 0.2683 & Gleasonian \\
\hline All & $\mathrm{T}$ & 42 & 168 & 197.6 & 12.8 & 2.32 & 0.0204 & 1334 & 1095.8 & 388.2 & -0.61 & 0.5394 & 2.12 & 0.0044 & - \\
\hline All & $\mathrm{K}$ & 66 & 325 & 384.8 & 19.5 & 3.06 & 0.0022 & 6293 & 3145.3 & 950.0 & -3.31 & 0.0009 & 1.44 & 0.1655 & Gleasonian \\
\hline All & A & 53 & 233 & 340.4 & 19.3 & 5.56 & $<0.0001$ & 6387 & 3127.8 & 1032.9 & -3.16 & 0.0016 & 1.66 & 0.0633 & Gleasonian \\
\hline All & W & 63 & 400 & 425.7 & 22.7 & 1.13 & 0.2591 & 6969 & 4705.3 & 1372.5 & -1.65 & 0.0991 & 1.18 & 0.3249 & Random \\
\hline All & $\mathrm{F}$ & 56 & 293 & 354.6 & 18.3 & 3.37 & 0.0008 & 5885 & 2942.4 & 977.6 & -3.01 & 0.0026 & 1.05 & 0.4264 & Gleasonian \\
\hline Strong & $\mathrm{N}$ & 31 & 117 & 149.2 & 9.9 & 3.24 & 0.0012 & 1428 & 595.7 & 228.9 & -3.64 & 0.0003 & 1.74 & 0.0263 & Clementsian \\
\hline Strong & $\mathrm{U}$ & 32 & 127 & 160.4 & 11.2 & 2.99 & 0.0028 & 1892 & 787.7 & 271.7 & -4.06 & $<0.0001$ & 2.51 & 0.0003 & Clementsian \\
\hline Strong & $\mathrm{E}$ & 31 & 109 & 168.7 & 12.6 & 4.74 & $<0.0001$ & 3552 & 1283.7 & 420.1 & -5.40 & $<0.0001$ & 2.20 & 0.0019 & Clementsian \\
\hline Strong & $\mathrm{T}$ & 21 & 66 & 83.4 & 8.1 & 2.14 & 0.0322 & 192 & 411.9 & 159.7 & 1.38 & 0.1685 & 1.62 & 0.0756 & - \\
\hline Strong & $\mathrm{K}$ & 32 & 132 & 167.1 & 12.6 & 2.79 & 0.0053 & 1712 & 1303.0 & 392.7 & -1.04 & 0.2976 & 1.83 & 0.0121 & - \\
\hline Strong & A & 24 & 93 & 134.6 & 10.7 & 3.89 & $<0.0001$ & 1974 & 1060.4 & 352.9 & -2.59 & 0.0096 & 0.49 & 0.0894 & Gleasonian \\
\hline Strong & $\mathrm{W}$ & 30 & 159 & 184.3 & 14.4 & 1.76 & 0.0784 & 2341 & 2052.6 & 592.4 & -0.49 & 0.6263 & 0.52 & 0.0483 & Random \\
\hline Strong & $\mathrm{F}$ & 22 & 112 & 117.5 & 9.9 & 0.56 & 0.5755 & 1036 & 810.8 & 280.1 & -0.80 & 0.4213 & 2.29 & 0.0008 & Random \\
\hline Weak & $\mathrm{N}$ & 24 & 119 & 137.8 & 10.8 & 1.75 & 0.0804 & 1319 & 910.3 & 301.9 & -1.35 & 0.1759 & 0.92 & 0.4207 & Random \\
\hline Weak & $\mathrm{U}$ & 33 & 128 & 187.3 & 13.3 & 4.45 & $<0.0001$ & 3483 & 1462.2 & 410.0 & -4.93 & $<0.0001$ & 0.63 & 0.1168 & Gleasonian \\
\hline Weak & $\mathrm{E}$ & 28 & 111 & 156.8 & 11.9 & 3.83 & 0.0001 & 3469 & 1239.6 & 385.7 & -5.78 & $<0.0001$ & 1.96 & 0.0038 & Clementsian \\
\hline Weak & $\mathrm{T}$ & 18 & 87 & 89.5 & 8.1 & 0.31 & 0.7599 & 609 & 513.1 & 167.7 & -0.57 & 0.5673 & 1.72 & 0.0107 & Random \\
\hline Weak & $\mathrm{K}$ & 31 & 156 & 175.7 & 12.3 & 1.60 & 0.109 & 2108 & 1282.5 & 382.4 & -2.16 & 0.0309 & 1.14 & 0.3232 & Random \\
\hline Weak & A & 26 & 113 & 158.0 & 13.3 & 3.39 & 0.0007 & 2408 & 1627.6 & 490.9 & -1.59 & 0.1119 & 1.50 & 0.0558 & - \\
\hline Weak & W & 30 & 164 & 190.1 & 13.9 & 1.87 & 0.0611 & 2775 & 1840.7 & 560.3 & -1.67 & 0.0954 & 0.74 & 0.2359 & Random \\
\hline Weak & $\mathrm{F}$ & 31 & 147 & 192.4 & 13.3 & 3.42 & 0.0006 & 3861 & 1806.9 & 557.5 & -3.68 & 0.0002 & 1.18 & 0.2630 & Gleasonian \\
\hline
\end{tabular}

